\title{
O futuro incerto dos partidos políticos argentinos
}

\author{
EDGARDO MOCCA
}

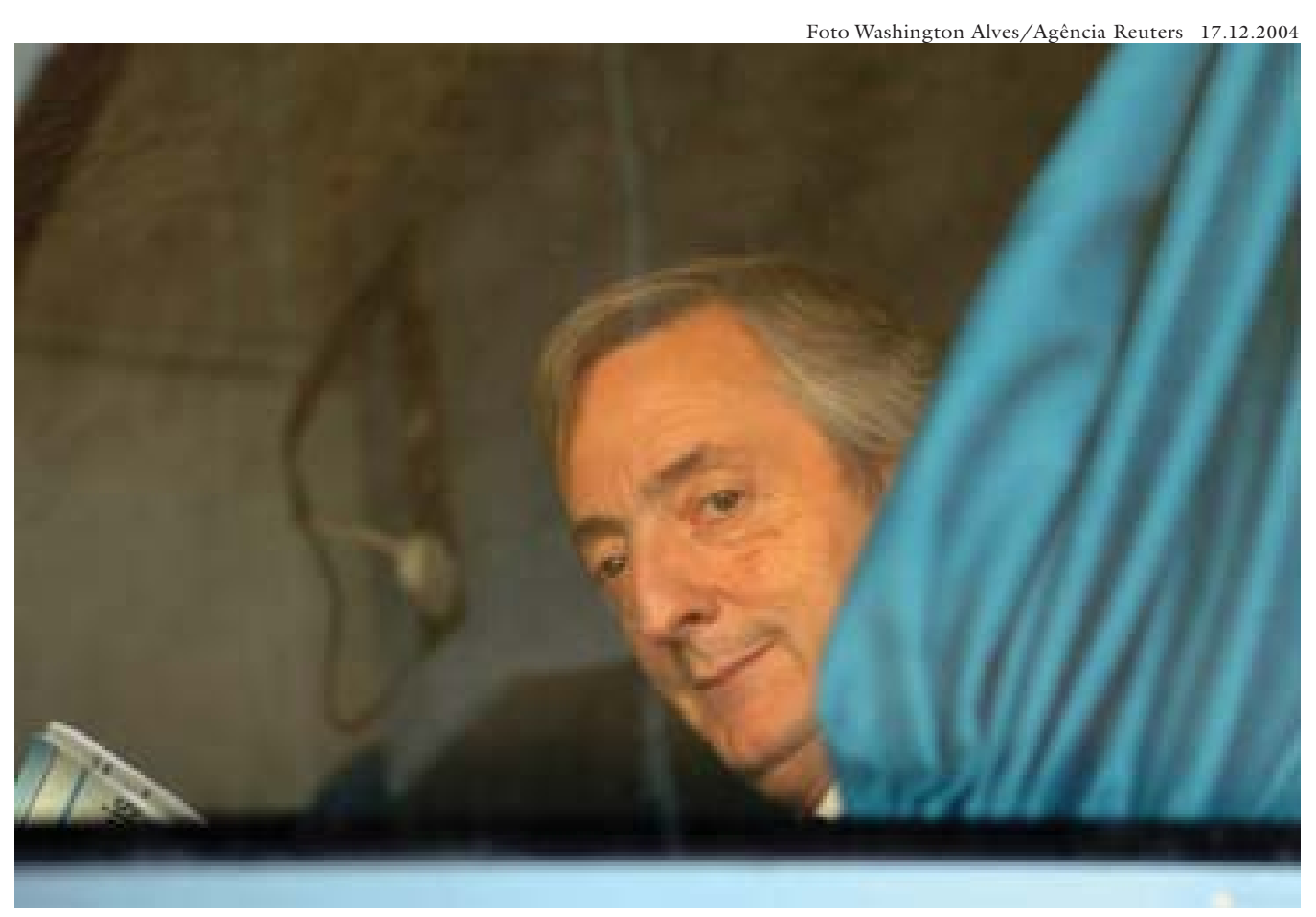

O presidente argentino Nestor Kirchner olha através da janela do ônibus em viagem pelo Brasil.

\footnotetext{
S ELEIÇões para renovação parlamentar realizadas no dia 23 de outubro podem marcar um ponto de inflexão no processo de relegitimação das 1 instituições democráticas depois da crise de 2001 - a mais intensa que a Argentina contemporânea atravessou.
}

A formulação de uma avaliação consistente do atual estado da democracia no país exige um balanço de sua conflitante história recente, dos discursos que circularam neste último período e o contrate entre os diagnósticos e prognósticos predominantes desde sua eclosão e o cenário real diante do qual nos encontramos. Fora dessa referência, corre-se o risco de simplificar o julgamento ou de ficar prisioneiro de dados e acontecimentos isoladamente considerados.

Os dois anos de governo de Kirchner foram uma etapa de recuperação de um centro de autoridade política e de solução satisfatória de alguns dos pontos mais urgentes da agenda de um país prostrado e à beira da dissolução. Estamos longe, no entanto, do país normal que o lema da equipe governante apregoa. $\mathrm{O}$ melhoramento dos principais indicadores econômicos (crescimento, superávit 
fiscal, arrecadação de impostos) não pode ocultar as ameaças de médio prazo que constituem as insuficiências do investimento produtivo, os perigos da inflação e a irresolvida questão da negociação com várias das empresas concessionárias dos serviços privatizados durante os anos de 1990; o apreciável melhoramento da situação do emprego e a diminuição dos índices de pobreza e indigência inscrevem-se no quadro de uma situação social de gravidade inédita na Argentina.

Por outro lado, a sustentação da legitimidade eleitoral e a convivência política pacífica e civilizada não podem ocultar a subsistência de uma grave brecha entre a sociedade e a política, assim como a persistência de práticas institucionais que, nascidas no calor de graves emergências, se instalaram como modos estáveis de funcionamento do poder no limite da legalidade constitucional, fenômeno que o politicólogo argentino Hugo Quiroga chamou“"emergência permanente" . Em última instância, depois de haver saído das profundezas do abismo econômico, social e político-institucional, o país não terminou de definir um rumo estável que o faça confiável perante o mundo e diante de seus próprios cidadãos.

O múltiplo desmoronamento de há quatro anos gerou prognósticos agoureiros e esperanças refundadoras. $\mathrm{O}$ curso dos acontecimentos não validou nem os profetas da dissolução nacional nem os augúrios de um novo começo histórico surgido das cinzas da velha política. A política argentina é, mais exatamente, um amálgama de continuidades e rupturas, de processos de longo prazo que se sustentam e permanecem, e insinuações de mudanças socioculturais e políticas profundas; o ciclo iniciado com a queda de De la Rúa em 2001 permanece aberto, embora tenham sido superadas suas facetas mais explosivas e destruidoras. Superada a incerteza sobre a subsistência da comunidade política como tal, sobrevive a interrogação sobre o grau de renovação que a convivência social e política dos argentinos alcançará.

Entre a multiplicidade de caminhos que se abrem a partir da interrogação assim formulada, este comentário se propõe a pensar, à luz dos acontecimentos desse convulsivo período, o futuro do sistema político argentino. A pergunta pelo porvir dos partidos políticos, envolvidos no descrédito coletivo, e pelo sistema de suas inter-relações é crucial para a reflexão sobre as perspectivas da democracia argentina. A previsibilidade política é um valor que a Argentina não pôde alcançar durante grande parte do século XX e que, uma vez recuperada a institucionalidade democrática em 1983, viu-se recorrentemente abalada pelo vendaval da crise.

Em fevereiro de 2002, o principal editorial do jornal La Nación (um dos mais importantes e influentes do país) criticava o fenômeno das "assembléias populares" e alertava sobre os perigos de que esses grupos se tornassem uma variante argentina dos sovietes, degenerassem no exercício da justiça com as próprias mãos e chegassem a constituir-se em um fator de "perturbação institucional"2. As assembléias haviam surgido em Buenos Aires e em outros conglomerados 
urbanos como formas organizativas quase totalmente espontâneas da sublevação popular desenvolvida nas críticas horas finais do governo de De la Rúa, no final de 2001. Eram a encenação de rua do pronunciamento eleitoral de outubro desse mesmo ano, quando mais de 4,5 milhões de cidadãos, um de cada quatro dos que foram às urnas, votaram em branco ou anularam deliberadamente seu voto.

A inédita comoção social, paralela aos saques de supermercados na região metropolitana de Buenos Aires, desenvolvia-se contra o pano de fundo da eclosão do plano de conversibilidade, a ruptura geral dos contratos e uma inédita deterioração dos indicadores sociais do país. Nesses dias, uma pesquisa realizada pelo PNUD na Argentina mostrava que os partidos políticos ocupavam o último lugar da confiança pública nas instituições: $94 \%$ das pessoas entrevistadas manifestavam ter pouca ou nenhuma confiança nos partidos políticos ${ }^{3}$. A indignação contra os políticos se manifestava em seu modo extremo por meio dos "escrachos", que consistiam em denunciar a presença de um político em algum lugar público e repudiá-lo de viva voz, sem que faltassem episódios de violência física.

O clima de idéias desses dias acompanhava ativamente a fúria popular. Os partidos políticos eram repudiados a partir dos mais diversos lugares do arco ideológico: a partir da direita, era promovida uma drástica diminuição numérica do Congresso, sem nenhuma atenção ao caráter inconstitucional de tal medida. Um artigo assinado por Rudi Dornbusch no' Financial Times, no qual se propunha que a Argentina cedesse o controle de seu sistema monetário, fiscal e de gestão de seus ativos por um longo período a um comitê de banqueiros de países centrais, tomando como modelo a experiência da Áustria depois da Segunda Guerra Mundial, foi objeto de comentários interessantes ${ }^{4}$. A partir de diferentes setores de esquerda, auspiciavam-se reformas políticas com viés direitista e unificadas conceitualmente pelo repúdio explícito da direção política em seu conjunto ${ }^{5}$.

Havia-se chegado assim ao ponto mais baixo do prestígio social dos partidos políticos, ao ponto de chegada de uma longa trajetória de deterioração desde que, em 1983, nos meses anteriores às primeiras eleições democráticas depois da ditadura militar emergida sete anos antes, registravam-se quase quatro milhões de novas filiações aos partidos políticos. $\mathrm{O}$ exame aprofundado das causas que foram minando paulatinamente o prestígio dos partidos políticos argentinos ultrapassa os propósitos deste trabalho. Das múltiplas perspectivas analíticas deste itinerário, revela-se particularmente'útil a que assinala as dificuldades para a gestão da crise econômica, cuja profundidade e caráter estrutural foram marcadamente subestimados no começo da recuperação democrática ${ }^{6}$. As enormes dificuldades para estabelecer uma agenda de cooperação entre as duas grandes forças políticas que reduzisse a intensidade do conflito expressivo geraram uma cena em que peronistas e radicais competiam para fazer iguais políticas a partir do governo e obstruir-se a partir da oposição ${ }^{7}$. A emergência foi o modo de 
existir de nossa democracia durante longos períodos a partir da crise hiperinflacionária: decretos de necessidade e urgência e, em geral, uma alta concentração dos recursos decisórios no Poder Executivo foram esvaziando a cena política de todo conteúdo deliberativo.

Um dos núcleos discursivos que acompanharam essa perda de significado do parlamento e da deliberação política foi a retórica antipolítica ${ }^{8}$. Menem fez desse recurso um dos núcleos discursivos de sua legitimação: havia que acelerar as mudanças, as únicas mudanças concebíveis - que eram as que ele punha em prática - contra os profissionais da obstrução, contra a máquina de impedir, ou seja, contra o Congresso e os partidos políticos. Vale esclarecer que a ofensiva contra a política não foi nesses anos patrimônio exclusivo da direita, para além de sua funcionalidade para o dogma do "pensamento único" neoconservador. A oposição de centro-esquerda, que teve um vertiginoso crescimento entre $1993 \mathrm{e}$ 1999, sob a direção de Chacho Álvarez, fundador e principal dirigente da Frente Grande e depois da Frepaso, adotou uma posição ambivalente diante do sistema de partidos existente na Argentina. Por um lado, instalou-se em um território pouco freqüentado pela esquerda, o de uma forte vocação republicana; apenas promovido ao centro da cena política pelo magnífico desempenho eleitoral nos comícios para a reforma constitucional de 1994, Álvarez rejeitou e enfrentou as posturas testemunhais que pretendiam o afastamento dos convencionais frentistas diante da "fraude perpetrada pelos partidos tradicionais", participou ativamente do debate constitucional e contribuiu de forma importante para seu conteúdo. Ao mesmo tempo, a agitação da necessidade de uma "nova política" nem sempre deixava claro a forma institucional que esta devia adotar; a insistência em constituir uma alternativa ao bipartidarismo tradicional nem sempre se traduzia na necessidade de um reagrupamento e uma reestruturação do sistema de partidos: era utilizada com freqüência em chave populista, como modo de sintonizar com uma atmosfera coletiva de recusa dos partidos políticos e de estabelecer uma clivagem pré-política entre honestos e corruptos. Muito antes que se revelasse, em 2000, a existência de graves casos de corrupção no governo, e particularmente no Senado Federal, diante dos supostos pagamentos de subornos para a aprovação da lei sindical, o prestígio da direção política (a "corporação política", começaram a chamá-la) havia entrado em um processo de franca erosão: sua impotência no manejo da crise, alimentada por seu comportamento nãocooperador e a cultura antipolítica haviam iniciado o caminho de seu declínio.

\section{Do colapso à saída eleitoral}

Depois da renúncia antecipada de De la Rúa, em 20 de dezembro de 2001, desenvolveu-se uma convulsiva saga de soluções falidas ao vazio presidencial; o caudilho de San Luis, Adolfo Rodríguez Sáa - designado em primeira instância pela Assembléia Legislativa'- renunciou após uma semana, quando a maioria dos governadores provinciais negou apoio a ele. No início de 2003, assumiu o exgovernador e então senador pela província de Buenos Aires, Eduardo Duhalde. 
Durante vários meses, o fantasma da ingovernabilidade percorreu o país, de mãos dadas com o caos econômico desencadeado pela brusca e espetacular desvalorização do peso, e a conversão em moeda nacional dos depósitos bancários e dívidas estabelecidas em dólares durante a vigência da conversibilidade do peso em dólar. A decisão por parte de Duhalde de encurtar seu próprio mandato, cuja conclusão estava prevista para dezembro de 2003, tomada depois que a repressão policial causara dois mortos em uma manifestação piqueteira ${ }^{9}$, revelou-se uma das chaves do êxito da transição comandada pelo caudilho bonaerense. A perspectiva de uma saída eleitoral próxima e carregada de incerteza em seu resultado estimulou condutas cooperativas por parte dos principais atores políticos daqueles dias.

Convém ressaltar o fato de que a democracia argentina tenha encontrado naqueles infaustos momentos recursos político-institucionais que lhe permitissem sobreviver em tão precárias e malfadadas condições. Sem dúvida, a não existência de forças radicalmente desleais ao sistema democrático com algum apoio social relevante apresentou-se como uma condição decisiva para essa conquista. Mas é necessário reconhecer que, mesmo em meio ao descalabro social e o vazio virtual de poder, os cidadãos argentinos mostravam uma importante reserva de fidelidade ao regime democrático ${ }^{10}$. A paulatina estabilização econômica e uma incipiente recuperação dos indicadores, depois de mais de três anos seguidos de recessão, também foram um fator favorável a uma precária normalização política.

Quando se inicia a etapa eleitoral, ocorre a mudança na situação dos partidos políticos. As pesquisas pré-eleitorais começavam a mostrar um quadro de acentuada fragmentação e incerteza, junto com uma marcada personalização da oferta, em detrimento do lugar central que os partidos políticos haviam ocupado nessa matéria desde 1983. Isidoro Cheresky caracterizou essa cena como de predomínio das "lideranças de popularidade" 1 . O radicalismo já não fazia parte das opções eleitorais centrais. Seu lugar foi ocupado por dois candidatos surgidos de suas filas: Ricardo López Murphy e Elisa Carrió, à frente de seus respectivos novos agrupamentos de centro-direita e centro-esquerda. Mas o drama central se desenvolvia no peronismo, em torno da reaparição em primeiro plano das expectativas de vitória eleitoral de Carlos Menem, que exercera a presidência entre 1989 e 1999. O presidente Duhalde viu-se obrigado a ensaiar diferentes alternativas no interior do Partido Justicialista para bloquear sua vitória. Uma manobra situada na própria fronteira da legalidade permitiria ao justicialismo driblar sua crise e a Duhalde enfrentar vitoriosamente a volta triunfal de Menem: a convenção partidária decidiu não resolver por eleições internas a candidatura justicialista e habilitou os três pré-candidatos para que se apresentassem nas eleições, não sem determinar que não podiam utilizar sua sigla e seus símbolos para esses fins. A eleição presidencial de abril de 2003 foi, na prática, uma disputa entre figuras, coalizões e agrupamentos criados para sustentar candidaturas circunstanciais, mais que uma competição entre partidos políticos. 
Depois do fracasso de outras tentativas, Duhalde decidiu apoiar a candidatura do então governador da província de Santa Cruz, Néstor Kirchner que, naquele momento, estava estruturando uma frente de centro-esquerda à margem da estrutura partidária. Alcançando o segundo lugar atrás de Menem no primeiro turno, com exíguos $22 \%$ dos votos, Kirchner concentrou rapidamente a seu redor a expectativa de uma ocasional e esmagadora maioria de eleitores para o segundo turno, de acordo com todas as sondagens eleitorais. Nessas condições, Menem produziu o que se pode considerar o ato político mais desleal desses vinte anos de democracia, ao retirar-se do segundo turno com a intenção de subtrair legitimidade de origem ao novo presidente, que havia feito da luta contra o "passado menemista" o eixo central de sua campanha proselitista.

Por caminhos sinuosos e não muito ortodoxos, constitucionalmente falando, a política argentina preservaria então um de seus capitais mais prezados, a legitimidade eleitoral. A reforma constitucional aprovada em 1994 havia consagrado um conjunto de modificações no capítulo dedicado ao modo de conformação e exercício da autoridade política, inspiradas no propósito de moderar o presidencialismo, dar mais estabilidade ao sistema democrático e facilitar a cooperação entre as forças políticas. A principal das novas figuras, a do Chefe de Gabinete, aparecia como um objeto de negociação que, em épocas de crise de governabilidade, pudesse ser utilizado para produzir mudanças na fórmula de governo sem o risco de ruptura institucional. Na prática, o regime político argentino acentuou seus traços presidencialistas e a solução da crise de 2001 adotou a forma de um "parlamentarismo de fato" sem que o lugar institucional do Chefe de Gabinete desempenhasse papel algum.

O regime político argentino oscila entre um presidencialismo decisório exercido na lógica da emergência permanente, quando a popularidade do presidente é alta, e um parlamentarismo que expressa a complexa e fragmentada estrutura federal, em épocas de crise e deterioração da figura presidencial ${ }^{12}$.

\section{As novidades políticas do governo de Kirchner}

A exígua porcentagem de votos obtidos no primeiro turno eleitoral, a não realização do segundo turno devido ao abandono de Menem, o peso decisivo do apoio de Duhalde e uma situação socioeconômica de extrema vulnerabilidade, embora em vias de recuperação, faziam prever a abertura de um período de fraqueza presidencial. Essa suposição constituía então um senso comum predominante entre comunicadores e analistas políticos. No entanto, desde seus primeiros dias como presidente, Kirchner adotou um estilo enérgico de decisões e construiu uma agenda política que fortaleceu o apoio dos cidadãos à sua gestão. A intervenção no Pami - a obra social dos aposentados, considerada um nicho de corrupção -, a apuração da cúpula do Exército, o impulso da renovação da Corte Suprema sobre a base de um método mais transparente que destacava as próprias faculdades presidenciais, a promoção da investigação do terrorismo de Estado durante a última ditadura militar, assim como uma posição negociadora 
firme e pragmática diante dos organismos internacionais de crédito e as empresas de serviços privatizadas foram algumas das iniciativas mais destacadas da primeira etapa; a posterior negociação bem-sucedida da dívida externa, que permitiu ao país sair da situação de suspensão de pagamentos, afirmaria a fortaleza do presidente diante da opinião pública. Foi essa relação com os cidadãos - uma relação mais exatamente virtual, que se expressou, antes de tudo, mediante as pesquisas de opinião - que permitiu a Kirchner administrar as tensões com o próprio partido de governo e, particularmente, com o setor afim a Eduardo Duhalde.

Curiosamente, ao cabo de um breve período inicial de governo, a crítica ao governo de Kirchner experimentou um deslocamento: passou do questionamento de sua condição de presidente fraco e com "poder emprestado" a pôr no centro da discussão o problema da hegemonia na prática de governo. Trata-se de um termo com uma grande capacidade de sensibilização em um país como o nosso, historicamente atravessado por projetos hegemônicos que, mesmo frustrados, cimentaram uma muito poderosa tradição política de intolerância e autoritarismo. Porém, a idéia de hegemonia tem significados diferentes segundo seja utilizada com relação ao regime político institucional, o rumo estratégico do governo ou os estilos com os quais se transita por esse rumo.

A presença de um "regime de partido hegemônico" pressupõe a existência de uma força política que, pela via da manipulação, a fraude e/ou a violência, consegue monopolizar todos os meios do poder ou a parte fundamental deles, vulnerando a divisão de poderes, esvaziando a oposição de recursos e bloqueando de modo absoluto a alternância no governo; não é suficiente para que se possa falar de "partido hegemônico" o fato de que uma das forças que competem eleitoralmente vença de maneira repetida na luta eleitoral (nesse caso, podese falar de um "partido predominante"), mas sim“é necessário que essa vitória possa ser tida como certa, dado o monopólio de recursos antes mencionado ${ }^{13}$. Não é esse o caso do governo que assumiu em 2003.

Hegemonia, na matriz gramsciana do termo, alude à pretensão de um determinado grupo político de fazer com que suas idéias ou orientações políticas se transformem em um senso comum da sociedade. Nesse ponto, pode-se reconhecer que houve uma mudança considerável entre as idéias neoliberais dominantes nos anos de 1990 e o atual clima de idéias no qual - mesmo sem a existência de um claro paradigma alternativo'- predomina o que se poderia caracterizar como "neodesenvolvimentismo" no sentido da revalorização do papel do Estado e da necessidade de um rumo produtivo com maiores margens de autonomia nacional. O importante é que essas mudanças de época se desenvolvam, como de fato ocorreu na Argentina, sem prejuízo da expressão de setores políticos circunstancialmente minoritários.

Por último, temos a questão dos estilos. É indubitável que nessa matéria o atual governo reproduz uma matriz decisória, na qual o papel do Congresso 
aparece sem clareza. Trata-se de uma prática sistêmica que se desenvolve sem solução de continuidade desde a crise hiperinflacionária de 1989 até nossos dias, e que aparece como uma interrogação para o futuro da qualidade democrática no país. Mas não seria justo atribuir a concentração presidencialista das decisões a um traço exclusivo do atual presidente, embora ele faça um uso ostensivo desse recurso. Sendo assim, a questão da hegemonia tem mais relação com uma legítima esgrima polêmica com relação aos estilos presidenciais do que com a insinuação de um risco sério para a institucionalidade democrática no país ${ }^{14}$.

\section{O futuro dos partidos políticos}

Com freqüência, a reflexão sobre a crise dos partidos políticos costuma discorrer com abstração das transformações que os modos de representação vêm atravessando em todas as democracias do mundo. Bernard Manim interpreta o fenômeno como "metamorfose da representação" 15 , posto que o termo "crise" perde sentido quando se pretende utilizá-lo para dar conta de fenômenos relativamente estabilizados; no entanto, como veremos, em nosso país assistimos efetivamente a uma profunda crise dentro de um fenômeno de mutação comum à vida política em todo o mundo.

A época de ouro dos partidos ficou no passado. Uma ampla e influente corrente de estudiosos sustenta que a função representativa dos partidos finca suas raízes em uma época distante e muito diferente da que nos cabe viver ${ }^{16}$. O enfraquecimento dos recursos políticos próprios dos Estados nacionais, a erosão das grandes identidades construídas em torno da relação com o mundo do trabalho e as enormes transformações das demandas contemporâneas no mundo cotidiano da população aparecem como premissas de uma crescente desafeição e descontentamento crescente quanto aos partidos políticos. Os partidos vêem reduzir-se o número de seus filiados, inclusive nos países com mais longa e profunda tradição partidária; sua militância ativa diminui paralelamente ao crescimento do abstencionismo eleitoral. Suas funções "tradicionais" enfraquecem. Já não são ferramentas insubstituíveis para a integração e mobilização da cidadania; a expressão de interesses tem nas democracias atuais múltiplos canais como diversos movimentos independentes e os meios de comunicação de massa. A formulação dos programas políticos de governo passa a ser, cada vez mais, patrimônio de especialistas e de organizações de caráter não político. Tampouco têm o monopólio como agência de recrutamento de líderes: os meios de comunicação e as pesquisas de opinião como fator de levantamento e construção da opinião pública facilitam a rápida emergência de figuras políticas alheias ao cursus honorum partidário $^{17}$.

Apesar de todas as transformações sumariamente enunciadas, os partidos conservam um papel no qual continuam sendo fundamentais e não têm rivais à vista: trata-se do papel procedimental de organização dos parlamentos e dos governos. Os partidos são instituições que organizam o acesso ao governo e que o exercem; são, nesse sentido, garantias da existência de uma democracia plural. 
Refugiados nesse papel, os partidos atuais deixaram de ser mediadores privilegiados da relação entre sociedade civil e Estado para ser virtualmente absorvidos por este último. É o que Mair chama partidos-cartéis, “caracterizados pela interpenetração entre partido e Estado, e por um padrão de colusão interpartidária"18. No contexto da hegemonia de uma concepção tecnocrática da administração do público, essa nova configuração aparece inevitavelmente associada a um comportamento corporativo e a um esvaziamento do sentido das instituições partidárias. No entanto, também é possível pensar que os partidos interpenetrados como estão à gestão estatal têm diante de si um desafio fundamental: constituirse em garantias de um sistema de alternativas efetivas de políticas públicas, capazes de assinalar rumos estratégicos e de fazerem-se responsáveis pelo resultado de sua posta em prática. Claro que isso pressupõe uma virada para um novo vínculo com a sociedade civil e para uma recuperação das capacidades autônomas da política.

De maneira que, se a pergunta pelo futuro dos partidos políticos na Argentina remetesse ao modelo das grandes forças expressivas de poderosas identidades político-culturais que se costumou chamar "partidos de massas", o tema poderia ser rapidamente encerrado com uma resposta negativa. Por outro lado, o tipo de partidos que agora parecemos desejar, fortemente implantado em termos ideológicos e programáticos, e autodefinido pela representação de uma classe em particular, nunca floresceu em nosso país. Os grandes partidos da Argentina moderna, diversamente, por exemplo, de seus pares chilenos, não se constituíram como partidos ideológicos ou de classe, mas como grandes movimentos pluriclassistas, com pretensões de representar o conjunto da nação. A institucionalização democrática do mais influente deles, o justicialismo, é, por outro lado, um evento relativamente recente. De modo que a figura do aparato de burocratas profissionais e a massa de militantes organicamente enquadrados e solidamente expressos pelos princípios e a ideologia do partido não merecem nenhuma nostalgia porque nunca existiram plenamente em nosso país, pelo menos entre as forças realmente influentes na política nacional.

Nos vinte anos de democracia, os dois grandes partidos - justicialista e radical - que organizaram o funcionamento do sistema político durante os breves e instáveis períodos democráticos da segunda metade do século XX caminharam na direção de estruturas essencialmente sustentadas pelos recursos dos diversos níveis e instâncias do Estado. Sua organização reproduz de modo bastante aproximado a organização do governo, seus quadros são predominantemente de funcionários ou ex-funcionários do Estado. Dos princípios de identificação que conformaram sua personalidade histórica, restaram vagas referências míticas, utilizadas com freqüência para fundamentar as mais diversas condutas políticas. O que era um eclipse gradual de seu prestígio social se converteu nos últimos anos em uma deterioração galopante até chegarem os dias do repúdio popular mais intenso e generalizado que nossa história democrática registra. 
No entanto, não assistimos a uma implosão do sistema de partidos políticos na Argentina. Afastadas da cena, como vimos, na eleição presidencial, as forças "tradicionais" da política argentina reapareceram nas eleições provinciais que se realizaram ao longo de 2003 e conseguiram uma continuidade na composição de ambas as câmaras legislativas realmente notável depois do terremoto social e político que o país viveu. Estamos, pois, diante de um cenário de mudanças e continuidades no sistema de partidos políticos; o radicalismo não pôde recompor, depois do dramático desenlace do governo de De la Rúa, uma liderança nacional que o coloque em condições de constituir-se em alternativa de governo; conserva o governo em cinco províncias e é a segunda força em ambas as câmaras do Congresso ${ }^{19}$.

A paisagem política diversificou-se com a emergência e crescimento de novas lideranças. Na centro-direita, as figuras do empresário Mauricio Macri e do ex-funcionário radical, Ricardo López Murphy, às quais se poderia somar, entre outros, o governador da província de Neuquém, Jorge Sobisch, parecem insinuar para esse setor um espaço de amplitude inédita na história recente do país. A centro-esquerda está sendo atravessada por um debate intenso em torno da atitude a ser tomada diante do governo de Kirchner: enquanto Elisa Carrió, à frente do ARI (Alternativa por una República Igualitaria), desenvolve um discurso fortemente antagônico frente ao governo, outras figuras relevantes como o dirigente socialista da província de Santa Fé, Hermes Binner, o prefeito da capital da província de Córdoba, Luis Juez, e o prefeito da cidade bonaerense de Morón, Martín Sabattella, entre outros, sustentam uma posição mais matizada que inclui apoios e críticas; um número considerável de quadros desse setor, provenientes fundamentalmente da Frepaso - força fundada por Carlos Chacho Álvarez e que co-governara na administração de De la Rúa -, somou-se às equipes de governo sem constituir, até o momento, uma força política própria de alguma relevância.

\section{O enigma peronista}

O governo de Kirchner é mais um governo peronista ou assinala o começo de um novo sistema de partidos políticos na Argentina? Como vimos, o atual presidente alcançou a vitória eleitoral com o apoio decisivo do peronismo bonaerense, encabeçado pelo então presidente Duhalde, depois de haver lançado sua candidatura por fora da estrutura justicialista e à frente de uma coalizão de centro-esquerda. Uma vez no governo, pôs em ação um conjunto de iniciativas que fazem parte, em termos genéricos, do repertório ideal do progressismo argentino; até se incluem nessa agenda temas como a reabertura dos julgamentos de um conjunto de chefes militares da última ditadura que haviam desaparecido do primeiro plano no discurso político desse setor. $\mathrm{O}$ presidente construiu sua retórica política em torno de um eixo central: a superação do passado menemista, identificado com a abertura indiscriminada da economia, a exclusão social, a corrupção e a deterioração institucional. 
Durante os primeiros meses de sua gestão, o presidente impulsionou o que se costumou chamar transversalidade. A ambigüidade do termo dá lugar a diferentes interpretações: desde o impulso a uma coalizão de centro-esquerda até uma nova versão do movimentismo peronista que absorveria em suas filas, discursivamente renovadas, amplos setores de esquerda ${ }^{20}$. Com o passar do tempo, foi perdendo-se o impulso da transversalidade, na medida em que Kirchner necessitava do respaldo parlamentar e político do justicialismo a sua ação de governo. De qualquer forma, a experiência eleitoral da província de Misiones e, sobretudo, a eleição do chefe de governo da cidade de Buenos Aires mostram a disposição da equipe governante para construir coalizões à margem e até antagônicas das estruturas formais do justicialismo.

Para as eleições parlamentares de 23 de outubro, Kirchner lançou no cenário uma nova formação política, a "Frente para la Victoria", que expressa as forças, justicialistas ou não, que apóiam sua gestão de governo. A realidade é diferente entre as províncias: enquanto em algumas o aparato peronista apóia os candidatos do presidente, em outras se opõe a eles; não faltam alguns casos nos quais os candidatos kirchneristas se dividem entre diferentes listas. Mas, de todos os cenários, sem dúvida o mais interessante é o que se apresenta na província de Buenos Aires; é aí que, com a candidatura central de Cristina Kirchner, senadora e esposa do presidente, o oficialismo enfrenta a candidatura de Hilda de Duhalde, deputada e esposa de quem seria o apoio decisivo para sua consagração ao primeiro mandato, Eduardo Duhalde. Ou seja, Kirchner enfrenta a estrutura formal do justicialismo no principal distrito do país. A fratura peronista em Buenos Aires foi precedida pelo deslocamento de numerosos quadros do aparato partidário duhaldista - entre eles vários prefeitos - para as filas do presidente. É inegável que a cena da província de Buenos Aires constitui uma novidade muito importante para o peronismo e para o conjunto do sistema político partidário argentino. Dois anos depois de haver protagonizado o fato inédito de apresentarse a eleições com três candidatos diferentes e antagônicos entre si, o justicialismo sofre uma fratura em um de seus principais bastiões.

Hegemonia, animosidades irredutíveis e ingovernabilidade parecem ser as chaves interpretativas predominantes sobre a atual crise peronista. Cada uma delas remete a períodos concretos de nossa história e ao comportamento do movimento fundado por Perón em cada um deles, a partir do olhar de seus adversários e críticos.

A hegemonia remete ao primeiro governo peronista assinalado por uma extrema polarização política - cujas ressonâncias continuam atravessando a cultura política argentina - e um avanço manifesto contra o pluralismo democrático, expresso em perseguições de partidos e imprensa opositora, assim como uma reforma constitucional de duvidosa legalidade e sem consenso parlamentar. Os partidários dessa leitura entendem que, por trás da querela bonaerense, há uma tentativa de assegurar ao Partido Justicialista as três bancadas em jogo no distrito. 


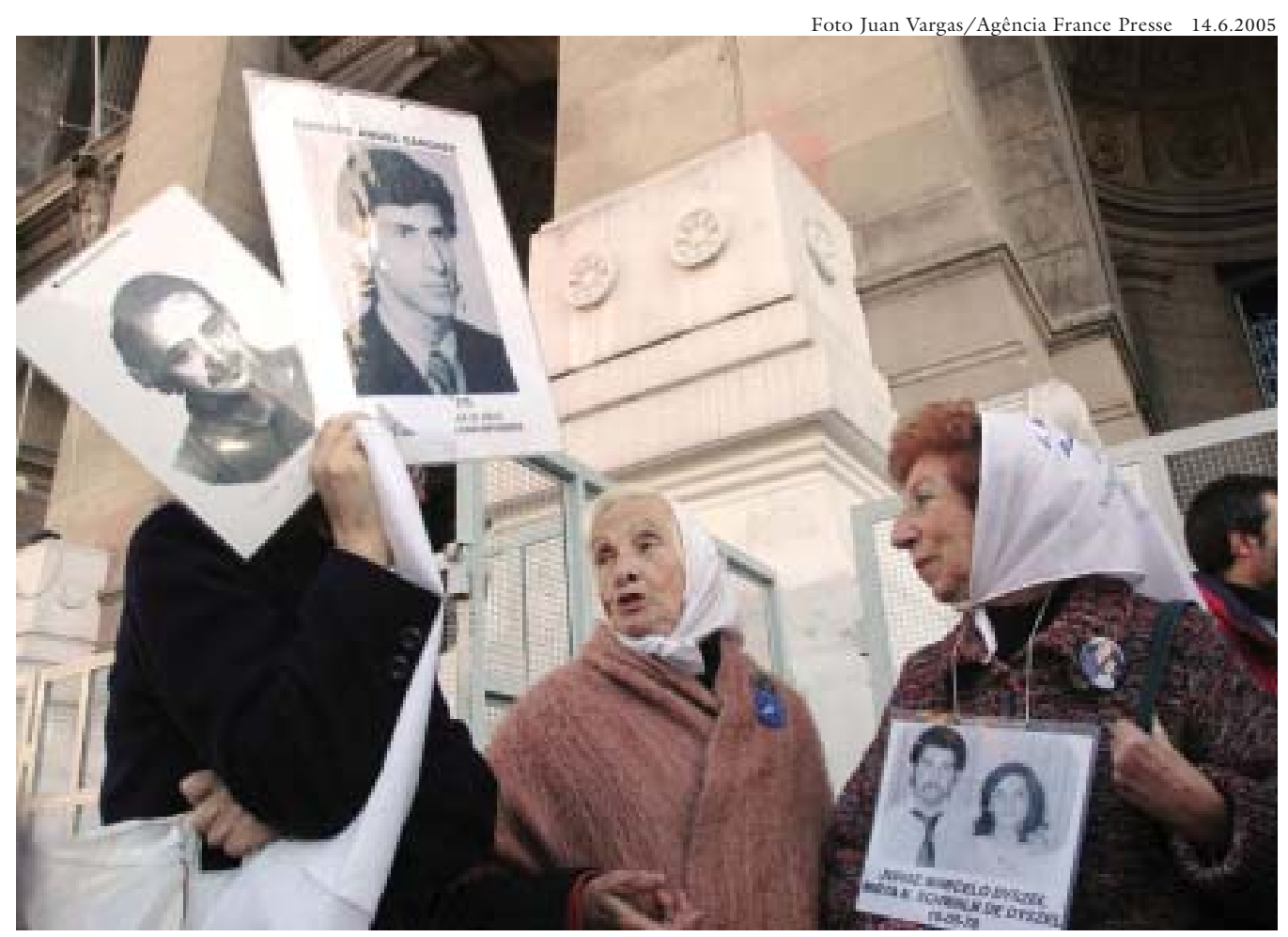

Integrantes do movimento Mães da Praça de Maio carregam cartazes de desaparecidos.

A alusão às animosidades irredutíveis, por sua vez, invoca a virtual guerra civil que setores do movimento situados nas antípodas ideológicas travaram durante os anos de 1970. Essa interpretação explica os fatos atuais pela supostamente congênita falta de limites por parte do peronismo para dirimir suas diferenças.

Por último, os temores pela governabilidade, no caso de uma fratura no justicialismo bonaerense, se apóiam na recente experiência do governo da Aliança, explicada em chave conspirativa como o produto de desordens cuidadosamente planejadas a partir da principal província do país. A prudência, segundo os aderentes a essa hipótese, aconselharia evitar a ruptura para aventar novas experiências de instabilidade e colapso institucional.

Cada um desses olhares tem certa ancoragem nos fatos de nossa história recente e não tão recente. No entanto, parecem ter em comum dois problemas conceituais: o relato de nossa história em termos excludentemente "panperonistas" - e, com freqüência, antiperonistas - (exatamente simétricos ao exaltado elogio dessa tradição que alguns de seus aderentes realizam) como se as tragédias argentinas se deixassem explicar sem o concurso de forças alheias e às vezes violentamente opostas ao peronismo e, em segundo lugar, certa prescindência do significado e das projeções políticas da crise do final de 2001.

De fato, o colapso que então pôs o país à beira da desintegração pareceu consumir-se no tempo sem produzir a esperável implosão do sistema político argentino. Os ecos da crise política continuam, no entanto, condicionando a 
conduta dos atores. As legendas partidárias que forneceram uma ordem, ainda que precária, à complicada transição posterior ao colapso, dificilmente podem, por si sós, prover a legitimidade necessária à democracia argentina em um futuro imediato.

A ofensiva bonaerense do presidente significa a expressão de uma vontade de reconfiguração do sistema de partidos na Argentina ou é uma simples luta de poder no interior do peronismo, sem conteúdo de idéias e projetos? A divisão do peronismo significará a erosão da governabilidade e a abertura de uma nova onda de instabilidade política ou será a abertura do caminho para um sistema de coalizões partidárias capazes de propor alternativas e de sucederem-se pacificamente no governo?

Está claro que o presidente e a equipe governante terão uma iniciativa decisiva no rumo dos acontecimentos. Tudo indica que a eleição de 23 de outubro significará uma ratificação da legitimidade do governo e uma melhor situação de seus apoios no Congresso, mesmo quando seguramente não alcançará uma maioria própria na Câmara dos Deputados, de modo que se ampliará sua capacidade de operação dirigida ao desenvolvimento de uma eventual nova coalizão de governo. A ruptura com as forças que correspondem ao ex-presidente Duhalde abre, no caso de projetar-se para o futuro, a possibilidade de que estas se reagrupem - como o fizeram nessas eleições ao concretizar uma aliança com a força conservadora liderada pelo ex-comissário Patti - com as expressões de centro-direita que saírem mais fortalecidas dessa eleição: a figura do empresário e dirigente do Boca Juniors, Mauricio Macri, com estreitos vínculos com o líder peronista de Buenos Aires, poderia encarnar uma parte importante desse reagrupamento. Mesmo assim, a hipótese de um reagrupamento político partidário em torno a duas coalizões situadas à direita e à esquerda do centro político tem que ser submetida à prova da prática política. Para que esse rumo se desenvolva, será necessário que as figuras mais representativas dos setores progressistas e conservadores considerem viável a construção de forças políticas independentes e ao mesmo tempo capazes de estabelecer uma interlocução inteligente com setores afins do justicialismo, sem demonizá-lo em seu conjunto nem subordinar-se a ele de maneira submissa.

O período que nos separa da próxima eleição presidencial em 2007 será, sem dúvida, decisivo para terminar de apreciar o potencial de mudança do sistema de partidos políticos argentino, depois da devastadora crise que sacudiu todos os seus atores.

Notas

1 Hugo Quiroga, La Argentina en emergencia permanente, Buenos Aires, Edhasa, 2005.

2 Editorial de La Nación, Buenos Aires, 14 fev. 2002. 
3 Juan Carlos Portantiero, Gerardo Adrogué, Agustina Grigera, Edgardo Mocca, Ana M. Mustapic e Osvaldo Pedroso, Desafios de la política, Informe sobre democracia en la Argentina, Buenos Aires, PNUD, 2002.

4 Ver Julio Nudler, "La candidata de Dornbusch", Página 12, Buenos Aires, 20 jul. 2002 .

5 Como exemplo desse clima de idéias, pode ser citada a circulação, em meados de 2002, de uma "Carta abierta de artistas e intelectuales argentinos por una asamblea constituyente", que se pronunciava "a favor de mudanças profundas que acabem com a ineficácia, a covardia e a desonestidade de nossos atuais representantes, que deliberam e governam em nosso nome, mas contra nossos interesses" e culminava propondo "um plebiscito obrigatório, aberto e livre, garantido e controlado por organismos internacionais, para eleger uma Assembléia Constituinte que estabeleça as bases de um novo sistema democrático, participativo e com firmes controles cidadãos no manejo dos assuntos públicos" (pode ser visto no site Bazaramericano.com).

6 Juan Carlos Torre, "El gobierno de la democracia en tiempos difíciles", Revista de Estudios Políticos, Nueva Época, Madrid, 1991.

7 Vicente Palermo, "El enemigo del pueblo", em Marcos Novaro (comp.), El derrumbe politico, Buenos Aires, Norma, 2002.

8 Edgardo Mocca, "Defensa de la política (en tiempos de crisis)", em Marcos Novaro (comp.), op. cit.

9 O chamado "movimento piqueteiro" consiste em uma série de organizações surgidas em meados dos anos de 1990 a partir de protestos de desempregados, concentrados principalmente no bloqueio de estradas e ocupação de ruas. Além de organizar o protesto e o reclamo, essas organizações - diversas e não-centralizadas - organizam a distribuição de uma importante proporção dos subsídios que o Estado concede aos chefes de família sem emprego.

10 Juan Carlos Portantiero, Gerardo Adrogué, Agustina Grigera, Edgardo Mocca, Ana M. Mustapic e Osvaldo Pedroso, op. cit.

11 Isidoro Cheresky, "En nombre del pueblo y de las convicciones: posibilidades y límites del gobierno sustentado en la opinión pública", revista Posdata, n. 9, Buenos Aires, set. 2003.

12 Edgardo Mocca, "Las reformas políticas en el laboratorio implacable de la crisis", Encrucijadas, revista da Universidad de Buenos Aires, set. 2004.

13 Ver Giovani Sartori, Partidos y sistemas de partidos, Madrid, Alianza Universidad, 1992.

14 Edgardo Mocca, “¿Hay un rumbo hegemónico?”, Clarín, Buenos Aires, 28 ago. 2003.

15 Bernard Manin, "Metamorfosis de la representación”, em ¿Qué queda de la representación politica?, Caracas, Clacso/ Nueva Sociedad, 1992.

16 Ver Mauro Calise, Il partito personale, Roma/ Bari, Laterza, 2000.

17 Peter Mair, ¿Tienen un futuro los partidos políticos?, Roma, Asociación CRS/ Democratici di Sinistra, 1999.

18 Ver Peter Mair, Party system changes, approaches and interpretations, Oxford, Clarendon Press, 1997.

19 Francisco Gutiérrez, "La batalla crucial que librará el peronismo", Clarín, Buenos Aires, 18 jun. 2004. 
RESUMO - A INÉDITA crise vivida pela Argentina entre o fim de 2001 e o início de 2002 constituiu uma séria ameaça para a estabilidade democrática do país. Este artigo se concentra nas conseqüências que a crise trouxe para o sistema de partidos políticos argentinos. Analisa-se como, contrariamente à maioria dos prognósticos, os partidos existentes não implodiram sob os efeitos do múltiplo desmoronamento. Igualmente, busca-se analisar as mudanças graduais que se foram produzindo na cena política, particularmente como conseqüência das novidades introduzidas pela gestão do presidente Kirchner. Esboça-se uma hipótese sobre as perspectivas de desenvolvimento do sistema de partidos a partir das eleições de outubro de 2005 (o artigo foi escrito antes dos comícios).

Palavras-Chave: Partidos políticos, Crise, Continuidade, Mudança, Peronismo, Centro-direita, Centro-esquerda, Eleições, Kirchner.

ABSTRACT - THE UNPRECEDENTED crisis in Argentina in late 2001 and early 2002 posed a serious threat to the country's democratic stability. This essay focuses the consequences of the crisis to the Argentinean political party system. It analyzes how, at odds with most forecasts, the existing parties did not implode as a result of the multiple collapse. It also seeks to analyze the gradual changes that took place in the political scene, particularly as a consequence of the President Kirchner's new policies. And it presents an outline of possible developments in the country's party system after this year's October elections (the essay was written before the political rallies).

KEY-WORDs: Political Parties, Crisis, Continuity, Change, Peronism, Center-Right, CenterLeft, Elections, Kirchner.

Edgardo Mocca é politólogo e professor de Teoria Política na Faculdade de Ciências Sociais da Universidade de Buenos Aires. Atua também como assessor na Subsecretaria de Integração Econômica para América e Mercosul na Chancelaria Argentina. Publica, com regularidade, notas de opinião nos jornais Clarín e Página 12 e na revista de atualidades políticas Debate. @-emocca@fibertel.com.ar

Tradução de Gênese Andrade. O original em espanhol - "El incierto futuro de los partidos políticos argentinos" - encontra-se à disposição do leitor no IEA-USP para eventual consulta.

Recebido em 28.09.05 aceito em 7.10.05. 